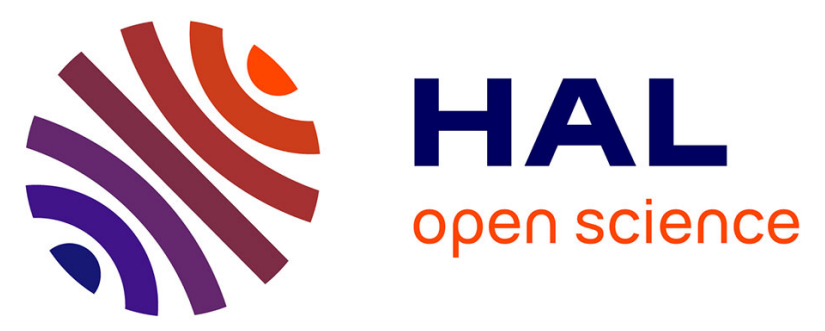

\title{
Assessing dietary intake in accordance with guidelines: Useful correlations with an ingesta-Verbal/Visual Analogue Scale in medical oncology patients
}

Estelle Guerdoux-Ninot, Nicolas Flori, Chloé Janiszewski, Arnaud Vaillé, Hélène de Forges, Bruno Raynard, Vickie E. Baracos, Simon Thezenas, Pierre Senesse

\section{To cite this version:}

Estelle Guerdoux-Ninot, Nicolas Flori, Chloé Janiszewski, Arnaud Vaillé, Hélène de Forges, et al.. Assessing dietary intake in accordance with guidelines: Useful correlations with an ingestaVerbal/Visual Analogue Scale in medical oncology patients. Clinical Nutrition, 2019, 38, pp.1927 1935. 10.1016/j.clnu.2018.06.974 . hal-03486725

\section{HAL Id: hal-03486725 \\ https://hal.science/hal-03486725}

Submitted on 20 Dec 2021

HAL is a multi-disciplinary open access archive for the deposit and dissemination of scientific research documents, whether they are published or not. The documents may come from teaching and research institutions in France or abroad, or from public or private research centers.
L'archive ouverte pluridisciplinaire HAL, est destinée au dépôt et à la diffusion de documents scientifiques de niveau recherche, publiés ou non, émanant des établissements d'enseignement et de recherche français ou étrangers, des laboratoires publics ou privés.

\section{(ㄷ)(1) $\$$}

Distributed under a Creative Commons Attribution - NonCommerciall 4.0 International 


\section{Full Length Article}

\section{Assessing dietary intake in accordance with guidelines: useful correlations}

3 with an ingesta-Verbal/Visual Analogue Scale in medical oncology patients

4 Estelle Guerdoux-Ninot ${ }^{1,2, *}$, Ph.D., Nicolas Flori ${ }^{2}$, M.D., Chloé Janiszewski ${ }^{2}$, MSc, Arnaud $^{2}$

5 Vaillé ${ }^{2}$, BSc, Hélène de Forges ${ }^{3}$, Ph.D., Bruno Raynard ${ }^{4}$, M.D., Ph.D., Vickie E. Baracos ${ }^{5}$,

6 PhD., Simon Thezenas ${ }^{6}$, MSc, and Pierre Senesse ${ }^{1,2}$, M.D., Ph.D.

$7 \quad{ }^{1}$ Department of Supportive Care, Cancer Institute of Montpellier (ICM), Montpellier,

8 France - University of Montpellier, France

$9 \quad{ }^{2}$ Department of Clinical Nutrition and Gastroenterology, Cancer Institute of Montpellier

10 (ICM), France - University of Montpellier, France

$11{ }^{3}$ Clinical Research Department, Cancer Institute of Montpellier (ICM), France - University

12 of Montpellier, France

$13{ }^{4}$ Department of Supportive Care, Gustave Roussy Cancer Campus, Villejuif, France

$14{ }^{5}$ Department of Oncology, University of Alberta, Canada

$15{ }^{6}$ Department of Biostatistics, Cancer Institute of Montpellier (ICM), France - University of 16 Montpellier, France

\section{* Corresponding author:}

Dr. Estelle GUERDOUX-NINOT

20 Institut régional du Cancer de Montpellier (ICM)

21 SIRIC, Pôle Soins de Support, Unité de Psycho-Oncologie

22 Parc Euromédecine

23208 avenue des Apothicaires

2434298 Montpellier 
25 France

26 Tel: +33(0)467612468

27 estelle.guerdoux-ninot@icm.unicancer.fr

28

29

30 Tables: 5

31 Figures: 4

32 References: 44

33 Abstract: 302 words

34 Text: 4439 words including Tables and figures

35

36

37 


\section{Abstract}

Background \& aims. Energy intake and food ingesta are central in nutritional screening and assessment. Cancer patients are at nutritional risk of losing weight, and clinicians need quick and easy tools to identify patients for nutritional support. This study aimed to evaluate the feasibility and the accuracy of a Visual/Verbal Analogue Scale of food ingesta (ingestaVVAS) to assess energy food intake and nutritional risk in medical oncology patients.

Methods. Dieticians administered prospectively the ingesta-VVAS in 1762 medical oncology patients. The external validity of the ingesta-VVAS was determined against daily energy intake based on a 24-hour dietary recall. Patients had to estimate how they currently ate on a scale from 0 "nothing at all" to 10 "as usual". Area Under the Receiver-Operating

Characteristics (ROC) curve served as determine the optimal cut-off and provide the discriminative power of the tool to detect patients who ingested less or more than $25 \mathrm{kcal} . \mathrm{kg}^{-}$ $50{ }^{1}$ day $^{-1}$.

51 Results. The feasibility of the ingesta-VVAS was $97.7 \%$. The scores were significantly correlated with energy intake $(\rho=.67, p<.05)$, whatever the specific situation (i.e. malnutrition or not). With a cut-off of $\leq 7$, the ingesta-VVAS exhibited a good power 54 discrimination (AUC $=.804$ ) to detect patients who ingested less or more than $25 \mathrm{kcal} . \mathrm{kg}^{-}$ $55{ }^{1}$.day ${ }^{-1}$, with a sensitivity of $80.8 \%$, a positive predictive value of $83.6 \%$, a specificity of $67.5 \%$, and a negative predictive value of $63.3 \%$. Patients with a score $\leq 7$ on the ingestaVVAS score were at 12-fold higher probability of nutritional risk [OR 12.3; 95\%CI (8.717.4); $\mathrm{p}<.001]$. Sensitivity to detect patients with a significant weight loss was $71 \%$, and a positive predictive value of $75.9 \%$.

Conclusions. This easy-to-use ingesta-VVAS is well-correlated with energy intake and may be useful in clinical practice. An ingesta-VVAS score is $\leq 7$ could be used to detect patients with nutritional risk of weight loss in medical oncology. 
63 Keywords: Ingesta; Nutrition; Cancer; Medical Oncology; Weight Loss; Visual Analogue 64 Scale 


\section{Introduction}

66 Decreased dietary intake, involuntary weight loss (WL) and nutritional symptoms are

67 frequent in oncology, affecting up to $85 \%$ of cancer patients [1-5]. Weight loss contributes

68 to poor prognosis, is closely related to anorexia, decreased calorie intake, skeletal muscle

69 wasting, and inflammation [6-8]. Recent guidelines recommend systematic nutritional

70 screening or assessment as well as a systematic follow-up of nutritional risk for all patients

71 undergoing anticancer treatment [9-11]. Furthermore, there is increasing evidence showing

72 that nutritional interventions significantly contribute to the prevention and reduction of WL

73 in oncology patients [11-13]. Therefore, assessing energy intake is a key piece of clinical

74 information to identify patients who would be candidates for nutritional support in

75 oncology.

76 Historically, clinicians have used different methodologies to assess the cancer patient's

77 nutritional status. For a long time, undernourished patients were defined using the

78 Nutritional Risk Index (NRI) in accordance with the Buzby's criteria [14]. Inflammatory

79 markers including albumin and $\mathrm{C}$ reactive protein (CRP) were also used in accordance with

80 the modified Glasgow Prognostic Score $[15,16]$. However, these markers and criteria were

81 inconsistently used. Levels of Body Mass Index (BMI) were often used to define

82 underweight, but again, the thresholds of clinical importance of these measures were

83 inconsistent [17]. The cut-off of 5\% of WL in medical oncology compared with the pre-

84 treatment weight (in particular a loss of lean tissue mass) is now accepted $[6,10,18]$.

85 In order to gather information about ingesta and energy intake, specific inquiries based on a

86 diet history over several days is a commonly-used approach [19]. However, this self-

87 administered form for recording food intake has several disadvantages. It requires the

88 implementation of dietary records during 3 to 7 days, is time consuming, effortful and costly 
89 [20]. One of the most reliable screening tools endorsed by cancer nutrition guidelines is the

90 Patient-Generated Subjective Global Assessment [21] (@ FD Ottery, 2001). The second item

91 of this questionnaire focuses on food intake, providing an ingesta score based on how the

92 patient self-rates his/her intake during the past month (choice between "unchanged", "more

93 than usual" and "less than usual"). However, clinicians needed more precise quantitative

94 information on energy intake to provide nutritional support defined by guidelines [9-11]. In

95 this context, Thibault et al. [22] demonstrated that ingesta-analogue scales could be useful

96 to estimate dietary intake in 114 patients, included cancer patients. If cancer patients could

97 reliably and accurately self-screen their energy intake by using this simple valid tool, they

98 would reduce the amount of health care professionals' work while becoming active in their

99 own disease. Therefore we aimed to proceed through a development process, including the

100 feasibility and the accuracy, of a Visual/Verbal Analogue Scale of food ingesta (ingesta-

101 VVAS) to assess energy food intake and nutritional risk of WL in medical oncology

102 patients.

103

\section{Methods}

\section{Participants}

106 This study is a part of a large prospective population-based dataset conducted in the Cancer

107 Institute of Montpellier (ICM) which is referral centre in France [23]. Since January 2009,

10811428 visits ( $n=4362$ patients) were screened in our cancer institute to assess their

109 nutritional status. Patients were eligible for inclusion in this cross-sectional study if they $1 /$

110 provided from January 2009 to December 2011 the diet history, the ingesta-VVAS score,

111 and the clinical characteristics (i.e., Eastern Cooperative Oncology Group performance

112 status, height, NRI, modified Glasgow Prognostic Score, current body weight, usual body 
113 weight), 2/ came for their first stay in our institute, 3 / were hospitalized for more than $48 \mathrm{~h}$,

114 and 4/ scheduled for a chemotherapy treatment. Patients were excluded if they $1 /$ were

115 hospitalized for surgery, 2/ had stopped oral intake because of a physician's prescription, 3/

116 received artificial nutrition (enteral or parenteral nutrition) or 4/ received oral nutritional

117 supplements. Forty-two patients who met inclusion criteria did not complete the ingesta-

118 VVAS. Data analysis was conducted on 1762 patients (Flowchart in Fig.1). The study was

119 carried out in accordance with the Declaration of Helsinki, and data were subject of an

120 official declaration to the CNIL, the French Data Protection Authority (methodological

121 reference MR-001).

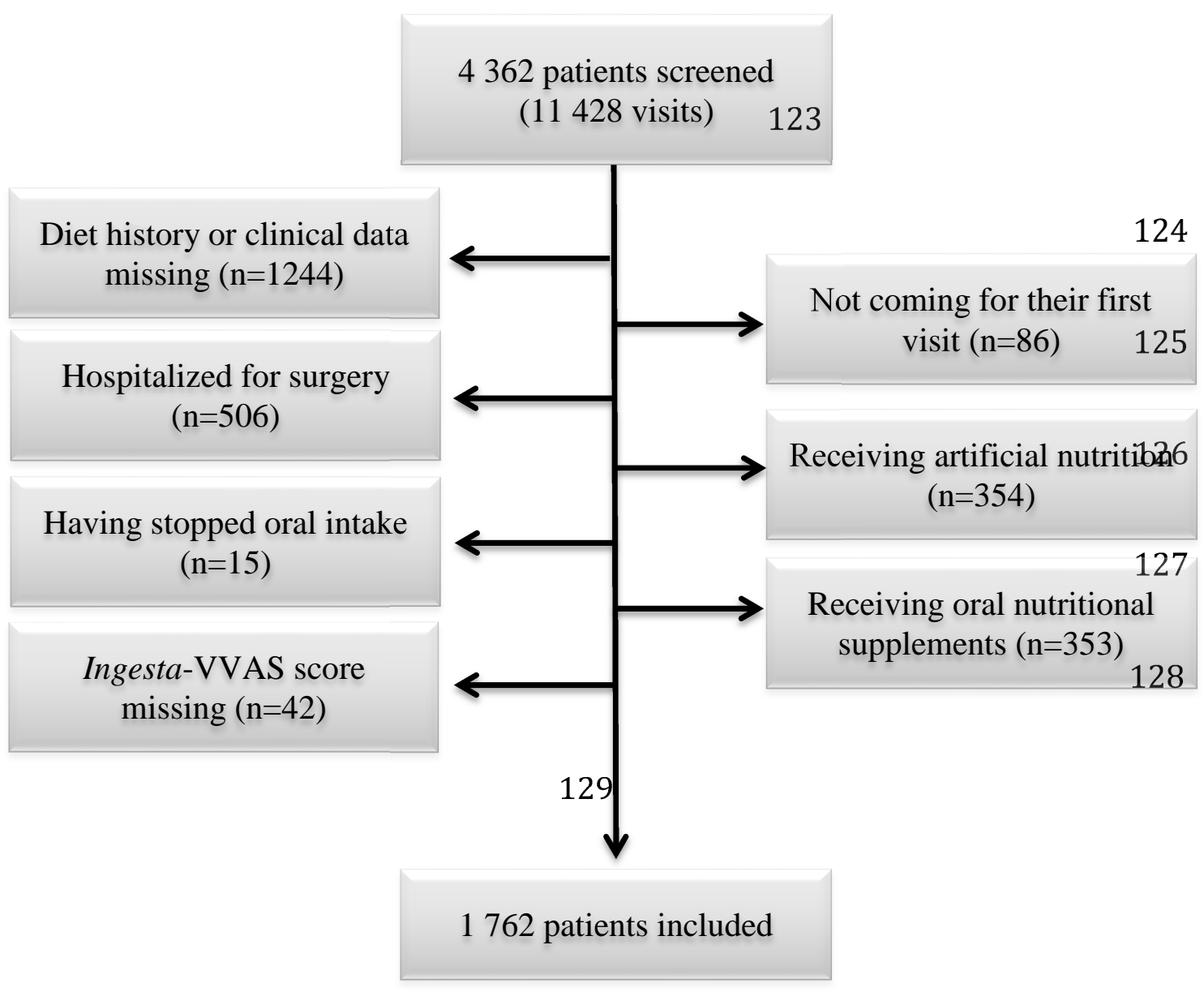

132 Fig. 1. Patients enrolled in the study according to the inclusion and non-inclusion criteria. 
134 A Visual Analogue Scale with verbal anchors was used for dietary intake [22]. Inquiries for

135 the ten-point ingesta-Verbal Analogue Scale were performed in French with the following

136 question "If you consider that, at times when you are in good health, you eat 10 out of 10,

137 how much do you currently eat on a scale from 0 to 10 ?". 0 would mean eating "nothing at

138 all" and 10 eating "as usual". For the patients who did not understand this oral question, the

139 dietician helped them in illustrating: "How do you currently eat at this moment: a quarter of

140 the usual amount, half the usual amount or three-quarters of the usual amount?". For the

141 ingesta-Visual Analogue Scale, the patients had to tick a 100-mm line traced on a paper to

142 answer the inquiry "How much do you currently eat on a scale from 0 "nothing" (far left

143 side of the line) to 10 "as usual" (far right side of the line)". The left extremity of the line

144 was anchored by "I eat nothing at all" $(0 \mathrm{~cm})$, the middle by "I eat half the usual amount" (5

$145 \mathrm{~cm})$, and the right extremity by "I eat as usual" $(10 \mathrm{~cm})$. The ingesta-Visual Analogue Scale

146 score was obtained by measuring the distance in centimeters from the far left side of the

147 scale (anchored "I eat nothing at all") to the point ticked by the patient (Fig. 2) and by

148 choosing the closest whole number.

149

150

151

152

153

154

If you consider that, at times when you are in good health, you eat 10 out of 10, how much do you currently eat on a scale from 0 to 10 ? 0 would mean "nothing at all" and 10 "as usual"

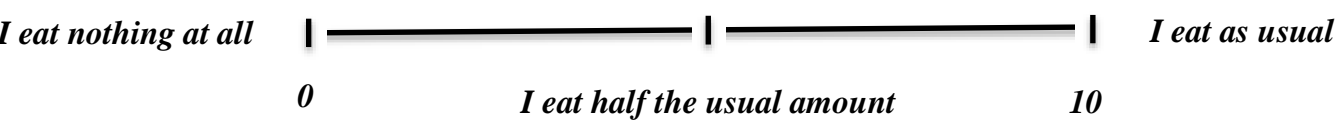

I eat half the usual amount

I eat as usual 10

Fig. 2. The ingesta-Visual Analogue Scale.

\section{Procedure}

Five dieticians completed the standardized forms edited by the Departments of Clinical 
155 Nutrition and Gastroenterology of the Cancer Institute of Montpellier to assess the patients'

156 nutritional status [23]. They first administrated the ingesta-VVAS in its verbal form. If the

157 patient did not understand the verbal form, then the patient was asked to perform the visual

158 form. Dieticians also collected: age, sex, type of cancer, current weight and weight loss

159 within the last month and the last 6 months, subjective weight loss (with the inquiry "Have

160 you experienced involuntary weight loss during the last 6 months?"), height, BMI, Eastern

161 Cooperative Oncology Group (ECOG) Performance Status score, albumin, C reactive

162 protein levels and daily energy intake.

163 The dietary record was based on a 24-hour recall (i.e., the day before the hospitalization),

164 conducted in an in-depth interview manner during 20 minutes. Detailed data about food

165 preparation methods, ingredients used in mixed dishes, and the brand name of commercial

166 products were explored. The amounts of each food consumed were estimated in reference to

167 a common size container, standard measuring cups and spoons. The experienced dietician

168 calculated energy intake based on the French food composition tables ${ }^{1}$ (in kcal.kg ${ }^{-1} \cdot \mathrm{day}^{-1}$ ).

169 To avoid any methodological bias, the performance of the ingesta-VVAS was randomized

170 either before or after the dietary 24-hour recall.

171 Percent WL was based on weight reported in the previous 6 months; if missing, the next

172 longest time frame for reported percent WL was substituted where available (i.e., usual body

173 weight, previous 3 or 2 months, or previous month). Based on international and French

174 definitions before treatment [24], the BMI were separated into three classes: low $(\leq 20)$,

175 intermediate (21-30) and high BMI (>30). WL was considered in accordance with the

176 historical cut-off of $\geq 5 \%$ compared with the patient's previous weight [6]. Undernourished

177 patients were defined on Nutritional Risk Index (NRI) in accordance with the Buzby's

\footnotetext{
1 The food composition tables are edited by the French « Centre d'Information sur la Qualité des Aliments (CIQUAL, Maisons-Alfort, France) », which belongs to the «Agence Française de Sécurité Sanitaire des Aliments (AFSSA)».
} 
178 criteria [14]. Inflammatory markers were also used to compute the modified Glasgow

179 Prognostic Score $[15,16]$.

180 In line with the Thibault et al.' study [22], different criteria were used as reference methods

181 to determine the external validity of the ingesta-VVAS but the daily energy intake served as

182 the primary criterion. Convergent data in the literature highlight that ingesting less than of

$18325 \mathrm{kcal} \cdot \mathrm{kg}^{-1} \cdot \mathrm{day}^{-1}$ is not enough to maintain a stable weight, whatever the type or grade of

184 cancer and treatment $[10,11,16,25-28]$. In order to determinate the accuracy of the ingesta-

185 VVAS for assessing the energy intake, patients were thus split in two sub-groups depending

186 on whether they ingested less or more than $25 \mathrm{kcal}^{\mathrm{kg}}{ }^{-1} \cdot \mathrm{day}^{-1}$.

\section{Statistical considerations}

188 Categorical variables were reported by means of frequencies and percentages. Means,

189 medians and range values were computed for continuous variables. The association between

190 the demographic and clinical characteristics features including the ingesta-VVAS, the

191 univariate statistical analyses were performed using the Pearson's Chi-square or the Fisher's

192 exact test, if applicable, and using the Kruskal-Wallis or Student T test. Logistic regressions

193 were used to determine whether the criteria were independent factors and to calculate the

194 regression equation. The Receiver Operating Characteristic curve was used to determine the

195 optimal cut-off of the ingesta-VVAS, defined with an dietary intake $<25 \mathrm{kcal} \cdot \mathrm{kg}^{-1} \cdot \mathrm{day}^{-1}$.

196 The area under the ROC curve served as establish the discriminative power of the tool [29].

197 Sensitivity, specificity, positive, and negative predictive values were weight up. All reported

$198 p$-values are two-sided and were considered significant at the 5\% level. Statistical analysis

199 was performed using the STATA v.11.0 software (Stata Corporation, College Station, TX,

200 USA). 


\section{Demographic and clinical characteristics, and nutritional status}

204 Our study included 1762 patients, of mean age 61.7 years ( \pm 12.9 years), ranging from 15 to

20596 years (Table 1). Primary cancers were localized in the gastro-intestinal tract $(26.5 \%)$,

206 breast (17.8\%), urological tract (14.7\%), lung (9.6\%) or head and neck $(9.1 \%)$,

207 gynecological $(8.6 \%)$ and others (13.7\%). Patients were metastatic in $73.1 \%$ of cases. Forty

208 percent of the patients $(n=704)$ had lost $10 \%$ or more of their usual weigh, and $60.2 \%$ of

209 patients $(\mathrm{n}=1051)$ had lost $\geq 5 \%$ compared with their previous weight [6]. The ingesta-

210 VVAS score was $\leq 7$ in $64.9 \%$ patients $(n=1144)$, while $35.1 \%$ had a score $>7(n=618)$. More

211 characteristics are presented in Table 1.

\section{Table 1}

213 Clinical and nutritional characteristics of the patients

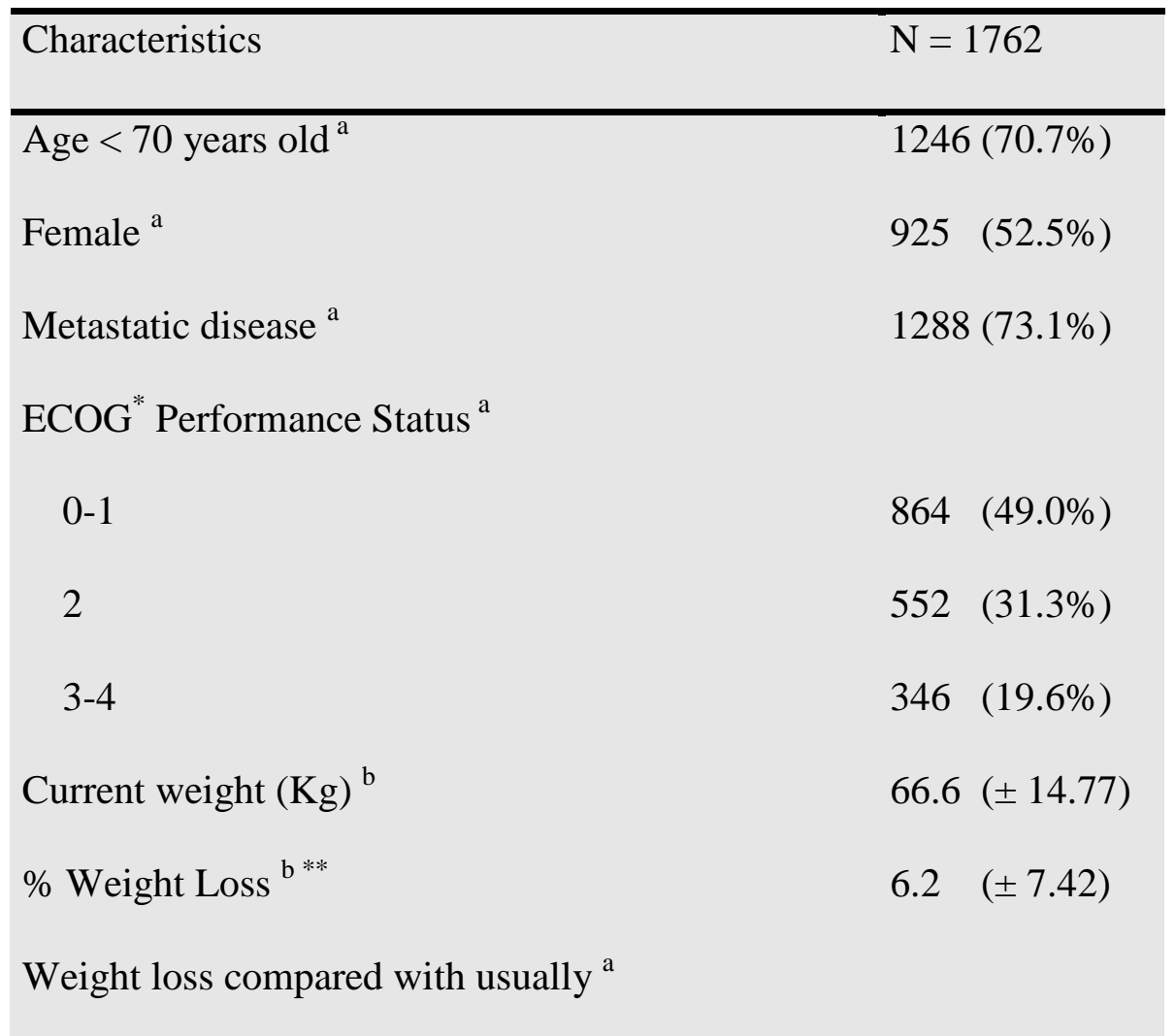




\begin{tabular}{|c|c|}
\hline$<5 \%$ & $694 \quad(39.4 \%)$ \\
\hline$[5-10 \%[$ & $347 \quad(19.7 \%)$ \\
\hline$[10 \% ; 15 \%[$ & $357 \quad(20.3 \%)$ \\
\hline$[15 \% ; 20 \%[$ & $181(10.3 \%)$ \\
\hline$\geq 20 \%$ & $166(9.4 \%)$ \\
\hline Subjective feeling of weight loss ${ }^{\text {a }}$ & $1163(66.6 \%)$ \\
\hline \multicolumn{2}{|l|}{ Body Mass Index (BMI) ${ }^{a}$} \\
\hline$\leq 20$ & $369(21.0 \%)$ \\
\hline $21-30$ & $1252(71.2 \%)$ \\
\hline$>30$ & $138(7.8 \%)$ \\
\hline \multicolumn{2}{|l|}{ Nutritional Risk Index (NRI) ${ }^{a}$} \\
\hline$<83.5$ (Major risk) & $189(13.2 \%)$ \\
\hline [83.5; 97.5] (Moderate-to-Low risk) & $658(46.1 \%)$ \\
\hline$>97.5$ (No risk) & $581 \quad(40.7 \%)$ \\
\hline \multicolumn{2}{|c|}{ Modified Glasgow Prognostic Score (m-GPS) ${ }^{a}$} \\
\hline 0 (Good prognostic) & $391(33.8 \%)$ \\
\hline 1 (Moderate prognostic) & $380(32.8 \%)$ \\
\hline 2 (Poor prognostic) & $387 \quad(33.4 \%)$ \\
\hline \multicolumn{2}{|l|}{ Ingesta-VVAS score $^{\text {a }}$} \\
\hline 1 & $(3.4 \%)$ \\
\hline 2 & $(5.0 \%)$ \\
\hline 3 & $152(8.6 \%)$ \\
\hline 4 & $117(6.6 \%)$ \\
\hline 5 & $372(21.1 \%)$ \\
\hline 6 & $141(8.0 \%)$ \\
\hline
\end{tabular}


Values are expressed as: ${ }^{\mathrm{a}} \mathrm{n}(\%),{ }^{\mathrm{b}}$ mean $( \pm \mathrm{SD}),{ }^{\mathrm{c}}$ median [area]; ${ }^{*}$ The Eastern Cooperative Oncology Group (ECOG) performance status refers to functional ability scores (ranged from 0 to 5 ) to quantify cancer patients general well-being and activities of daily life; ** Percent weight loss was based on weight reported in previous 6 months; if missing, the next longest time frame for reported percent weight loss was substituted where available (i.e., usual body weight, previous 3 or 2 months, or previous 1 month). Percent weight loss was calculated as follows: [(current weight in $\mathrm{Kg}$ - previous weight in $\mathrm{Kg}$ )/previous weight in $\mathrm{kg}$ ] x 100 .

\section{Feasibility of the Visual/Verbal Analogue Scales of food ingesta}

222 The feasibility of the verbal form of the ingesta-VVAS was 95\% ( $\mathrm{n}=1674)$. The use of the

223 visual form was necessary in second intention for $5 \%$ of patients $(n=88)$ who did not

224 understand the oral question. Only 42 patients who met the inclusion criteria were unable to complete the verbal or visual ingesta-VVAS. Thus, the feasibility for the ingesta-VVAS was $97.7 \%(\mathrm{n}=1762)$.

\section{Accuracy of the ingesta-VVAS for assessing dietary intake}

228 Correlation coefficients between the ingesta-VVAS scores and the mean daily energy intake

229 were positive and significant $(\rho=.67, p<.05)$ (Fig. 3). The linear regressions may offer

230 moderately-to large predictive values with adjusted- $\mathrm{R}^{2}$ of respectively .51 as followed: mean 231 energy intake $\left(\mathrm{kcal} \cdot \mathrm{kg}^{-1} \cdot \mathrm{day}^{-1}\right)=2.3 *$ ingesta-VVAS score +5.9 . 


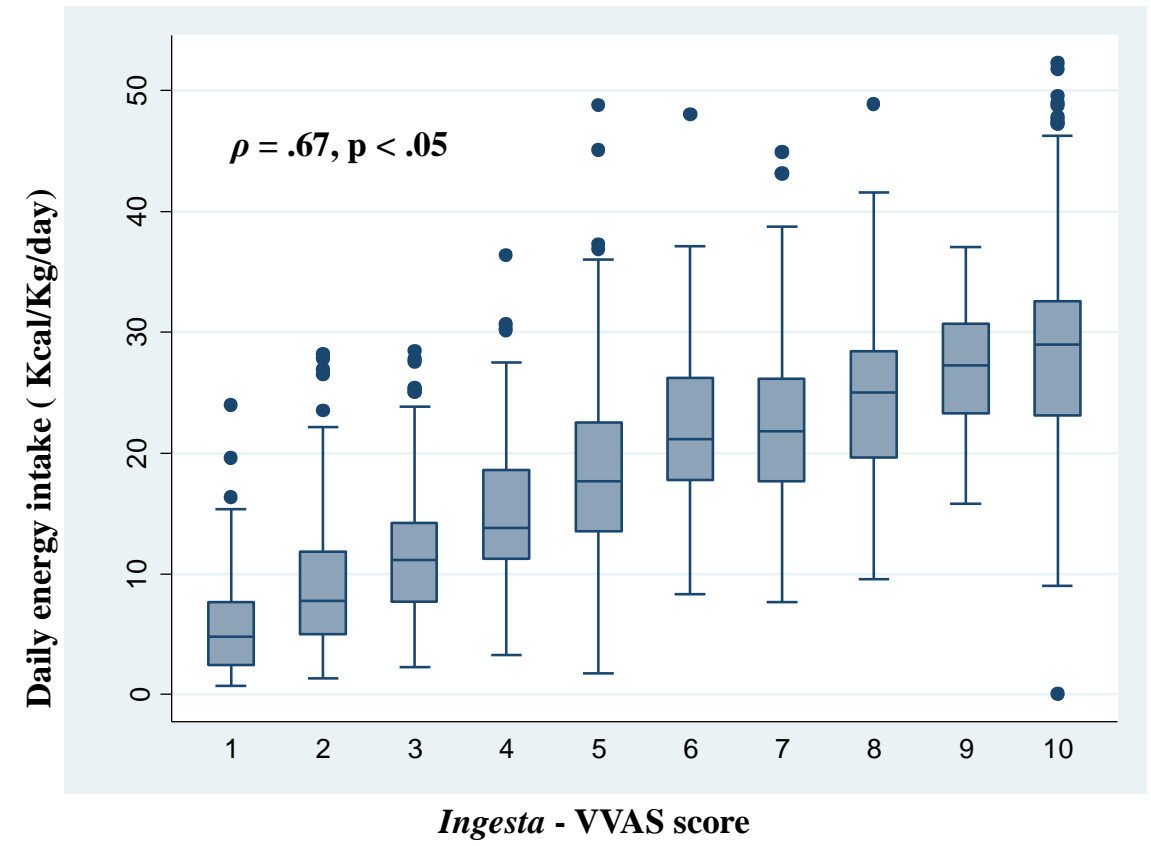

Fig. 3. Statistical correlation between ingesta -Verbal/Visual Analogue Scale (ingesta -

234 VVAS) and daily energy intake, calculated from a 24-hour dietary inquiry and expressed as $235 \mathrm{kcal} \cdot \mathrm{kg}^{-1} \cdot \mathrm{day}^{-1} \cdot \rho=$ Spearman correlation coefficient

237 We also conducted correlations between mean daily energy and the ingesta-VVAS scores, 238 in different patients subgroups (i.e., depending on their WL, their BMI and their NRI). All 239 the coefficients between groups remained relevant, significantly moderate or high $(p<.001)$ : $240 \rho=.67$ in patients who had lost $\geq 5 \%$ compared with their previous weight, $\rho=.68$ in 241 undernourished patients (defined by a NRI below 97.5), $\rho=.70$ in overweight patients 242 (defined by a BMI >30), $\rho=.71$ in underweight patients (defined by a BMI below or equal to $24320)$, and $\rho=.74$ in patients with a major nutritional risk (NRI <83.5).

\section{Accuracy of the ingesta-VVAS for assessing nutritional risk}

245 Two thirds $(67.1 \%)$ of patients $(\mathrm{n}=1183)$ ingested less than $25 \mathrm{kcal} \cdot \mathrm{kg}^{-1}$.day ${ }^{-1}$. Taking into 246 account these data, the optimal cut-off of the ingesta-VVAS determinate with the ROC 247 curve was $\leq 7$, with a $95 \%$ confidence interval (Fig. 4). The area under the ROC Curve was 


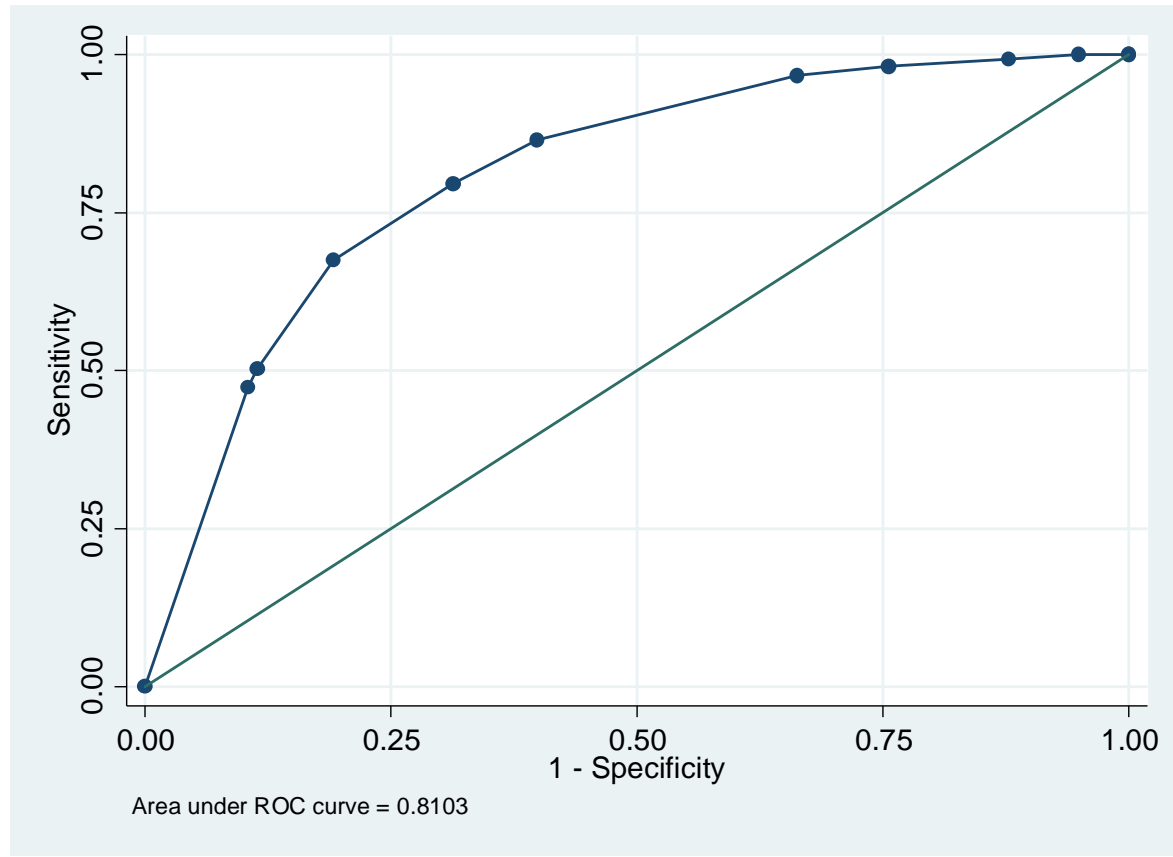

250 Fig.4. Receiver Operating Characteristic curve.

251 The results of univariate analysis presented in Table 2 indicate that age, gender, presence of

252 metastases, ECOG Performance Status, subjective feeling of weight loss, WL, BMI, m-GPS,

253 NRI, and ingesta-VVAS scores are associated ( $\mathrm{p}<.001)$ with a nutritional risk (i.e., patients

254 ingesting less than $\left.25 \mathrm{kcal} \cdot \mathrm{kg}^{-1} \cdot \mathrm{day}^{-1}\right)$.

\section{Table 2}

257 Relationships between nutritional risk (defined as food intake $<25 \mathrm{kcal} \cdot \mathrm{kg}^{-1}$.day ${ }^{-1}$ ) and

258 clinical data

\begin{tabular}{|c|c|c|c|c|}
\hline Clinical data & $\begin{array}{l}\text { Patients }(\%) \text { with a } \\
\text { nutritional risk } \\
(\text { ingesta }<25 \\
\left.\text { kcal.kg }^{-1} \cdot \mathrm{day}^{-1}\right)\end{array}$ & Odds Ratio & $\begin{array}{c}{[95 \%} \\
\text { Confidence } \\
\text { Intervalle] }\end{array}$ & P-Value \\
\hline
\end{tabular}




\begin{tabular}{|c|c|c|c|c|}
\hline$<70$ & 64.5 & 1 & & \\
\hline$\geq 70$ & 73.5 & 2.77 & $2.28-3.36$ & $<0.001$ \\
\hline \multicolumn{5}{|l|}{ Gender } \\
\hline Male & 64.2 & 1 & & \\
\hline Female & 69.8 & 2.32 & $2.01-2.66$ & $<0.001$ \\
\hline \multicolumn{5}{|l|}{ Metastatic disease } \\
\hline No & 56.3 & 1 & & \\
\hline Yes & 71.1 & 2.46 & $2.18-2.78$ & $<0.001$ \\
\hline \multicolumn{5}{|l|}{ ECOG Performance Status } \\
\hline $0-1$ & 53.8 & 1 & & \\
\hline 2 & 75.5 & 3.09 & $2.54-3.75$ & $<0.001$ \\
\hline $3-4$ & 87.0 & 6.69 & $4.89-9.15$ & $<0.001$ \\
\hline \multicolumn{5}{|c|}{ Subjective feeling of Weight Loss } \\
\hline No & 53.9 & 1 & & \\
\hline Yes & 73.4 & 2.76 & $2.43-3.15$ & $<0.001$ \\
\hline \multicolumn{5}{|l|}{ Weight Loss } \\
\hline$<5 \%$ & 63.8 & 1 & & \\
\hline$\geq 5 \%$ & 68.6 & 2.18 & $1.94-2.47$ & $<0.001$ \\
\hline \multicolumn{5}{|l|}{ BMI } \\
\hline$\leq 20$ & 50.1 & 0.44 & $0.35-0.56$ & $<0.001$ \\
\hline $21-30$ & 69.7 & 1 & & \\
\hline$>30$ & 90.6 & 4.19 & $2.03-2.59$ & $<0.001$ \\
\hline \multicolumn{5}{|l|}{ NRI } \\
\hline$<83.5$ & 74.1 & 1.63 & $1.12-2.35$ & 0.009 \\
\hline$[83.5 ; 97.5]$ & 70.8 & 1.38 & $1.09-1.76$ & 0.008 \\
\hline$>97.5$ & 63.7 & & & \\
\hline \multicolumn{5}{|l|}{ m-GPS } \\
\hline 0 (Good prognostic) & 56.8 & 1 & & \\
\hline 1 (Moderate prognostic) & 70.8 & 2.42 & $1.94-3.02$ & $<0.001$ \\
\hline 2 (Poor prognostic) & 81.4 & 4.37 & $3.39-5.65$ & $<0.001$ \\
\hline \multicolumn{5}{|l|}{ Ingesta-VVAS score } \\
\hline$\leq 7$ & 83.6 & 8.75 & $6.98-10.98$ & $<0.001$ \\
\hline$>7$ & 36.7 & 1 & & \\
\hline
\end{tabular}

259 ECOG: Eastern Cooperative Oncology Group; BMI: Body Mass Index; NRI: Nutritional Risk Index; m-GPS:

260 Modified Glasgow Prognostic Score; Ingesta-VVAS: Visual/Verbal Analogue Scale of food ingesta

261 The cut-off of $\leq 7$ on the ingesta-VVAS detected $83.6 \%$ of the patients who had a nutritional

262 risk $(\mathrm{n}=956)$. The main data are reported in Table 3. The sensitivity and the positive

263 predictive value were $80.8 \%$ and $83.6 \%$, respectively, while the specificity and the negative

264 predictive value were $67.5 \%$ and $63.3 \%$, respectively. 
Table 3

266 Assessment of nutritional risk (defined as food intake $<25 \mathrm{kcal}^{\mathrm{kg}} \mathrm{kg}^{-1} \cdot \mathrm{day}^{-1}$ ) using the

267 Verbal/Visual Analogue Scale of food ingesta (ingesta-VVAS).

268

\begin{tabular}{llll}
\hline & Nutritional risk & Low nutritional risk & Total (n) \\
& $\left(\right.$ ingesta $<25{\left.\mathrm{kcal} . \mathrm{kg}^{-1} . \mathrm{day}^{-1}\right)}$ & $\left(\right.$ ingesta $\left.\geq 25 \mathrm{kcal} \mathrm{kg}^{-1} \cdot \mathrm{day}^{-1}\right)$ & \\
\hline Ingesta-VVAS $\leq 7$ & $956(\mathrm{TP}) 80.8 \%$ & $188(\mathrm{FP}) 32.5 \%$ & $\mathbf{1 1 4 4}$ \\
Ingesta-VVAS $>7$ & $227(\mathrm{FN}) 19.2 \%$ & $391(\mathrm{TN}) 67.5 \%$ & $\mathbf{6 1 8}$ \\
Total (n) & $\mathbf{1 1 8 3}$ & $\mathbf{5 7 9}$ & $\mathbf{1 7 6 2}$ \\
\hline
\end{tabular}

TP: true-positives; FP: false-positives; FN: false-negatives; TN: true-negatives

271 In multivariate analysis (Table 4), the main independent criteria to predict nutritional risk

272 (defined as food intake $<25 \mathrm{kcal} \cdot \mathrm{kg}^{-1} \cdot \mathrm{day}^{-1}$ ) were: age, ECOG Performance Status, m-GPS,

273 BMI and ingesta-VVAS scores. Patients with a score $\leq 7$ on the ingesta-VVAS score were

274 at 12-fold higher probability of nutritional risk [OR 12.3; 95\%CI (8.7-17.4); $\mathrm{p}<.001]$.

275 Obesity (BMI >30) was associated with an increased risk of ingesting less than $25 \mathrm{kcal} \mathrm{kg}^{-}$

$276{ }^{1}$.day $^{-1}$ [OR 5.7; 95\%CI (2.7-11.8); $\left.\mathrm{p}<.001\right]$. Bad prognostic $(\mathrm{m}-\mathrm{GPS}=2)$ was significantly

277 associated with a nutritional risk [OR 1.67; 95\%CI (1.1-2.5); $\mathrm{p}<.001]$.

$279 \quad$ Table 4

280 Predictive factors independently associated with nutritional risk (defined as food intake $<25$

$281 \quad \mathrm{kcal} . \mathrm{kg}^{-1} \cdot \mathrm{day}^{-1}$ ) 


\begin{tabular}{|c|c|c|c|}
\hline Risk factors & Odds Ratio & [95\% Confidence Intervalle] & P-Value \\
\hline \multicolumn{4}{|l|}{ Age (in years old) } \\
\hline$<70$ & 1 & & \\
\hline$\geq 70$ & 1.58 & $1.10-2.27$ & 0.014 \\
\hline \multicolumn{4}{|l|}{ ECOG Performance Status } \\
\hline $0-1$ & 1 & & \\
\hline 2 & 1.12 & 0.549 & $0.77-1.64$ \\
\hline $3-4$ & 1.68 & 0.015 & $1.10-2.55$ \\
\hline \multicolumn{4}{|l|}{ BMI } \\
\hline$\leq 20$ & 0.25 & $0.17-0.37$ & $<0.001$ \\
\hline $21-30$ & 1 & & \\
\hline$>30$ & 5.70 & $2.75-11.83$ & $<0.001$ \\
\hline \multicolumn{4}{|l|}{ m-GPS } \\
\hline 0 (Good prognostic) & 1 & & \\
\hline 1 (Moderate prognostic) & 1.12 & $0.77-1.64$ & 0.549 \\
\hline 2 (Poor prognostic) & 1.68 & $1.10-2.55$ & 0.015 \\
\hline \multicolumn{4}{|l|}{ Ingesta-VVAS score } \\
\hline$\leq 7$ & 1 & & \\
\hline$>7$ & 12.32 & $8.73-17.39$ & $<0.001$ \\
\hline
\end{tabular}

ECOG: Eastern Cooperative Oncology Group; BMI: Body Mass Index; NRI: Nutritional Risk Index; m-GPS:

Modified Glasgow Prognostic Score; Ingesta-VVAS: Visual/Verbal Analogue Scale of food ingesta

\section{Accuracy of the ingesta-VVAS for assessing significant weight loss}

287 Furthermore, about two-thirds $(60.2 \%)$ of patients $(n=1051)$ exhibited a weight loss $\geq 5 \%$

288 compared with their usual weight. The cut-off of $\leq 7$ on the ingesta-VVAS detected $71 \%$

$289(\mathrm{n}=868)$ of these patients. More details are presented in Table 5. The sensitivity and the

290 positive predictive value were $71 \%$ and $75.9 \%$, respectively, while the specificity and the

291 negative predictive value were $48.8 \%$ and $42.6 \%$, respectively. 


\section{Table 5}

296 Assessment of undernutrition (defined as weight loss $\geq 5 \%$ compared with the usual weight) using the Verbal/Visual Analogue Scale of food ingesta (ingesta-VVAS).

\begin{tabular}{llll}
\hline & Undernutrition & "Normal" nutrition & Total (n) \\
& $(\mathrm{WL} \geq 5 \%)$ & $($ No WL or WL <5\%) & \\
\hline Ingesta-VVAS $\leq 7$ & $868(\mathrm{TP}) 71 \%$ & $276(\mathrm{FP}) 51,2 \%$ & $\mathbf{1 1 4 4}$ \\
Ingesta-VVAS $>7$ & $355(\mathrm{FN}) 29 \%$ & $263(\mathrm{TN}) 48,8 \%$ & $\mathbf{6 1 8}$ \\
Total (n) & $\mathbf{1 2 2 3}$ & $\mathbf{5 3 9}$ & $\mathbf{1 7 6 2}$ \\
\hline
\end{tabular}

Notes: WL: Weight Loss; TP: true-positives; FP: false-positives; FN: false-negatives; TN: true-negatives

\section{Discussion}

302 In line with the Patient-Generated Subjective Global Assessment [21] and the 10-points 303 analog scales [22], this ingesta-VVAS was developed as a clinically practical tool to assess 304 food intake and nutritional risk of WL. Feasibility and accuracy were determined with a 24305 hour dietary recall for ingesta in a large and a representative prospective sample of 1762 306 medical oncology patients. Main results showed an excellent feasibility of the ingesta-

307 VVAS. Positive and significant correlation coefficients were found between the ingesta-

308 VVAS score and the mean daily energy intake. These correlations were not modified 309 according to specific situations of malnutrition (i.e., in different patients subgroups 310 including WL, BMI and NRI criteria). With a cut-off of $\leq 7$, the ingesta-VVAS exhibited a

311 good power discrimination to detect patients who showed a nutritional risk (i.e., who 312 ingested less $25 \mathrm{kcal} \cdot \mathrm{kg}^{-1} \cdot \mathrm{day}^{-1}$ ), and also patients who had a significant weight loss (i.e., $\geq$ $3135 \%$ compared with their usual weight).

314 A recent review of appetite and food intake methodology [30] concluded that visual 
analogue scales are currently the most established tools to assess subjective appetite.

316 However, "appetite" or "anorexia" (like mentioned in the last version of the Common

317 Terminology Criteria for Adverse Events) have no consistent meaning for patients and are in 318 any case not the same thing as food intake. Thibault et al. [22] had already shown that a 10319 point VVAS was feasible and valid to quickly assess dietary intakes in hospitalized patients.

320 This is why French guidelines for cancer management recommended the use of food intake 321 ingesta-VVAS for nutritional screening [10, 23, 26]. Both the verbal and visual versions of 322 the ingesta-VVAS are feasible. Although a dedicated tool (EPA® or SEFI® in its English 323 version), based on Thibault's study [22], has been approved by the French Society for 324 Clinical Nutrition and Metabolism, a written analog scale was preferred here. We aimed to 325 test the feasibility and the accuracy of a very simple tool (i.e. a verbal form of ingesta-

326 VVAS and a 'paper' visual analogue scale) that can be available as much as possible for the 327 worldwide clinicians. Furthermore, the feasibility and usefulness of visual analogue scales 328 in cancer patients have already been documented for the assessment of appetite [31, 32], 329 palatability [33], pain [e.g., 34, 35] and fatigue [36] as well as other symptoms [37]. As 330 Aitken [38] suggested, "people seem to like using this sort of scale and readily understand 331 its requirements. It takes only seconds to obtain a score and imposes no inconvenience" to 332 the patient. Thus, ingesta-VVAS is an interesting tool with a good ecological validity ${ }^{2}$. It 333 enables the patients' subjective nutritional sensations to be measured and quantified [39].

334 Cost effectiveness using the ingesta-VVAS as a first-line screening patients at risk is also 335 very interesting compared with a $24 \mathrm{~h}$ recall. In the present study, using a stratified approach 336 could have saved 558 hours of dietitian time (587.3 hours to do the $24 \mathrm{~h}$ recall in 1762

\footnotetext{
${ }^{2}$ An ecologically valid measure has characteristics similar to a naturally occurring behavior and can predict everyday function [39], with two requirements: (1) verisimilitude: the demands of a test and the testing conditions resemble demands in the everyday world of the patient; and (2) veridicality: the performance on a test predicts some aspects of the patient's functioning on a day-to-day basis.
} 
337 patients vs. 29.4 hours to use the VVAS), thus saving $15272.46 €\left(587.33 * 27.37^{3}\right)$. Many

338 institutions do not have staff to do the $24 \mathrm{~h}$ recall whereas clinicians can use the ingesta-

339 VVAS worldwide as a first-line screening.

340 Recent data in literature highlight that an intake $<25 \mathrm{kcal}_{\mathrm{kg}}{ }^{-1} \cdot \mathrm{day}^{-1}$ is not enough to

341 maintain a stable weight, whatever the type or grade of cancer and type of treatment [11]. In

342 our study, more than two thirds of the patients ingested less than $25 \mathrm{kcal} \mathrm{kg}^{-1} \cdot \mathrm{day}^{-1}$. The

343 ROC curves detected an optimum cut-off of $<8$ divided this population exactly in three and

344 one-quarter in accordance with the tool validated by the French society. The ingesta-VVAS

345 for assessing energy intake is very sensitive and exhibits a high positive predictive value: in

346 medical oncology patients, the probability of not eating enough when the ingesta-VVAS

347 score is 8 is $83.6 \%$, (which can be considered as a good quality [40]). In multi-adjusted

348 model, ingesta-VVAS score, age, ECOG Performance Status, m-GPS and BMI remained

349 significantly and independently associated with nutritional risk (defined as food intake $<25$

$350 \mathrm{kcal} \cdot \mathrm{kg}^{-1} \cdot \mathrm{day}^{-1}$ ). Nutritional risk is 12 -fold higher in patients exhibiting a score $\leq 7$ on the

351 ingesta-VVAS than patients with a score $\geq 8$. Obesity $(\mathrm{BMI}>30)$ was associated with an

352 increased risk of ingesting less than $25 \mathrm{kcal} \cdot \mathrm{kg}^{-1}$.day ${ }^{-1}$. It underlines that having a BMI >30

353 is not a guarantee of maintaining a stable weight. Obesity is not a protection against under

354 nutrition. However, these results should be taken with caution. Indeed, the energy intake is

355 calculated on the standardized weight for a theoretical BMI of 25 to 30 [41].

356 Concerning the assessment of WL, which was not the first goal, the positive predictive value 357 was good with $75.9 \%$. As the sensitive value was $71 \%$, one can guess that repeated

358 measures of ingesta-VVAS may probably permit to provide a better sensitivity on time.

359 These results are also in line with the physiopathology of WL in medical oncology (i.e., first 360 anorexia then WL). Using a cut-off of $10 \%$ of WL, two European surveys found that 30-

3 The hourly cost for a dietitian in France is $27.37 €$. 
$40 \%$ of cancer patients were malnourished. In line with recent guidelines $[6,8]$, the cut-off

362 of $\geq 5 \%$ compared with the patient's previous weight (and not $10 \%$ ) was taking into

363 account, that explained $60.2 \%$ of patients were found to be undernourished in this study. All

364 these patients already warrant some nutritional intervention. A score of 7 (or less) at the

365 ingesta-VVAS has allowed detecting $71 \%$ of these undernourished patients. Those results

366 suggest using the ingesta-VVAS tool in the remaining group of patients to potentially plan

367 some earlier nutritional intervention.

368 Several limitations could be pointed out in our study. First, Thibault et al. [22] followed the

369 Burke and al. [42] dietary historical method based on a 3-day food intake, whereas our

370 inquiry was based only on one day. However, a simple 24-hour recall, or structured 24-hour

371 recall, or a 7-day estimated record or open-ended food diary give similar values [43].

372 Epidemiologic studies showed that any single method cannot assess dietary exposure 373 perfectly [20]. In practice, given our sample size and the practical burden of a 3-7 day

374 dietary record, we can guess that it would have been unfeasible to use in research or in 375 clinical practice. Another weakness may be that the interviewer - who was aware of the 376 results of the 24-hour dietary recall - was the same clinician who performed the ingesta-

377 VVAS. This "not-blinded design" may not be a major bias because the patients directly and 378 blindly responded to the inquiries, the dietary recall and the ingesta assessment, with a low 379 dietician's influence, in a randomized order. Then, validity and accuracy the cut-off were 380 assessed using patient recall of information about diet and weight. This chose was based on 381 the findings that self-reporting of weight and 24-hour dietary recall may be valid and 382 reliable measurements to identify malnutrition in patients [20, 44]. Of course, those self383 reports depend on the patients' memory and the skills of a well-trained dietician to minimize 384 recall bias. The notion of a simple continuous scale to assess the subjective perception of 385 food intake as a potential screen for clinically significant malnourishment is worth pursuing, 
but additional work seems to be needed in terms of content and concurrent validation,

387 reliability testing, responsiveness to change, and the value of a cutoff score that would 388 suggest clinical action. Also, it would be interesting to study the ingesta-VVAS values as a 389 function of the WL grades and BMI level as defined recently by Martin and al.[8]. Finally, 390 even if the tool may offer very good psychometric proprieties, it is intended for screening 391 and not as a substitute for assessment by a nutritional professional.

392 In conclusion, food intake screening is central in nutritional assessment. Clinicians have to 393 detect ingesta deficits, which is the major way to predict risk of WL in cancer patients. This 394 study confirms a valid and clinically practical tool, the ingesta-VVAS, for a quick 395 estimation of dietary intake in medical oncologic patients, easy to use by verbal form on 396 worldwide. According to its properties, it may be very helpful to identify patients who 397 would be candidates for nutritional support in prevention and supportive care.

399 Acknowledgments: The authors are grateful to the dietetic staff for their assistance with 400 patient recruitment toward the end of the study and their support in completing the study: 401 Stéphanie Arnac, Berénice Clavié, Laure Francioni, and Anne Fallières. They also thank 402 Drs. Vanessa Guillaumon and Jean-Pierre Bleuse, and Pr. Marc Ychou for their support.

404 Conflict of interest: The authors declare that they have no financial or non-financial 405 competing interests.

407 Statement of authorship: EGN participated in performed some statistical analyses, drafted 408 the manuscript and provided intellectual content. CJ and AV carried out the collection of 
409 data. ST performed the statistical analyses. VB, HF and BR participated in the design of the

410 study and revised the manuscript critically for important intellectual content. PS and NF

411 conceived the study, carried out the collection of data and drafted the manuscript.

412

413 Funding: This study was supported by the SIRIC Montpellier Cancer (Grant

414 INCa_Inserm_DGOS_12553), which was not involved in study design; in the collection,

415 analysis and interpretation of data; in the writing of the report; and in the decision to submit

416 the article for publication. All authors critically reviewed the manuscript and approved the

417 version for submission.

418 


\section{References}

1. Coa KI, Epstein JB, Ettinger D, et al (2015) The Impact of Cancer Treatment on the Diets and Food Preferences of Patients Receiving Outpatient Treatment. Nutr Cancer 67:339-353 . doi: 10.1080/01635581.2015.990577

2. Bozzetti F, on behalf of the SCRINIO Working Group (2009) Screening the nutritional status in oncology: a preliminary report on 1,000 outpatients. Support Care Cancer 17:279-284 . doi: 10.1007/s00520-008-0476-3

3. Guerdoux-Ninot E, Kilgour RD, Janiszewski C, et al (2016) Meal context and food preferences in cancer patients: results from a French self-report survey. SpringerPlus 5: . doi: 10.1186/s40064-016-2538-1

4. Hébuterne X, Lemarié E, Michallet M, et al (2014) Prevalence of malnutrition and current use of nutrition support in patients with cancer. JPEN J Parenter Enteral Nutr 38:196-204 . doi: 10.1177/0148607113502674

5. Mariani L, Lo Vullo S, Bozzetti F, SCRINIO Working Group (2012) Weight loss in cancer patients: a plea for a better awareness of the issue. Support Care Cancer Off J Multinatl Assoc Support Care Cancer 20:301-309 . doi: 10.1007/s00520-010-1075-7

6. Fearon K, Strasser F, Anker SD, et al (2011) Definition and classification of cancer cachexia: an international consensus. Lancet Oncol 12:489-495 . doi: 10.1016/S14702045(10)70218-7

7. Fearon KC, Voss AC, Hustead DS, Cancer Cachexia Study Group (2006) Definition of cancer cachexia: effect of weight loss, reduced food intake, and systemic inflammation on functional status and prognosis. Am J Clin Nutr 83:1345-1350

8. Martin L, Senesse P, Gioulbasanis I, et al (2015) Diagnostic Criteria for the Classification of Cancer-Associated Weight Loss. J Clin Oncol 33:90-99 . doi:

10.1200/JCO.2014.56.1894 
9. August DA, Huhmann MB, American Society for Parenteral and Enteral Nutrition (A.S.P.E.N.) Board of Directors (2009) A.S.P.E.N. clinical guidelines: nutrition support therapy during adult anticancer treatment and in hematopoietic cell transplantation. JPEN J Parenter Enteral Nutr 33:472-500 . doi: 10.1177/0148607109341804

10. French Speaking Society of Clinical Nutrition and Metabolism (SFNEP) (2014)

Clinical nutrition guidelines of the French Speaking Society of Clinical Nutrition and Metabolism (SFNEP): Summary of recommendations for adults undergoing non-surgical anticancer treatment. Dig Liver Dis 46:667-674 . doi: 10.1016/j.dld.2014.01.160

11. Arends J, Bachmann P, Baracos V, et al (2016) ESPEN guidelines on nutrition in cancer patients. Clin Nutr. doi: 10.1016/j.clnu.2016.07.015

12. Lee JLC, Leong LP, Lim SL (2015) Nutrition intervention approaches to reduce malnutrition in oncology patients: a systematic review. Support Care Cancer 24:469-480 . doi: $10.1007 / \mathrm{s} 00520-015-2958-4$

13. Mueller C, Compher C, Ellen DM, the American Society for Parenteral and Enteral Nutrition (A.S.P.E.N.) Board of Directors (2011) A.S.P.E.N. Clinical Guidelines: Nutrition Screening, Assessment, and Intervention in Adults. J Parenter Enter Nutr 35:16-24 . doi: $10.1177 / 0148607110389335$

14. Buzby GP, Williford WO, Peterson OL, et al (1988) A randomized clinical trial of total parenteral nutrition in malnourished surgical patients: the rationale and impact of previous clinical trials and pilot study on protocol design. Am J Clin Nutr 47:357-365 15. Leitch EF, Chakrabarti M, Crozier JEM, et al (2007) Comparison of the prognostic value of selected markers of the systemic inflammatory response in patients with colorectal cancer. Br J Cancer 97:1266-1270 . doi: 10.1038/sj.bjc.6604027

16. Forrest LM, McMillan DC, McArdle CS, et al (2003) Evaluation of cumulative prognostic scores based on the systemic inflammatory response in patients with inoperable 
non-small-cell lung cancer. Br J Cancer 89:1028-1030 . doi: 10.1038/sj.bjc.6601242

17. Jensen GL, Hsiao PY, Wheeler D (2012) Adult nutrition assessment tutorial. JPEN J Parenter Enteral Nutr 36:267-274 . doi: 10.1177/0148607112440284

18. Dewys WD, Begg C, Lavin PT, et al (1980) Prognostic effect of weight loss prior to chemotherapy in cancer patients. Eastern Cooperative Oncology Group. Am J Med 69:491497

19. Kumanyika SK, Mauger D, Mitchell DC, et al (2003) Relative validity of food frequency questionnaire nutrient estimates in the Black Women's Health Study. Ann Epidemiol 13:111-118

20. Shim J-S, Oh K, Kim HC (2014) Dietary assessment methods in epidemiologic studies. Epidemiol Health e2014009 . doi: 10.4178/epih/e2014009

21. Ottery FD (1996) Definition of standardized nutritional assessment and interventional pathways in oncology. Nutr Burbank Los Angel Cty Calif 12:S15-19

22. Thibault R, Goujon N, Le Gallic E, et al (2009) Use of 10-point analogue scales to estimate dietary intake: A prospective study in patients nutritionally at-risk. Clin Nutr 28:134-140 . doi: 10.1016/j.clnu.2009.01.003

23. Senesse P, Isambert A, Janiszewski C, et al (2017) Management of Cancer Cachexia and Guidelines Implementation in a Comprehensive Cancer Center: A Physician-Led Cancer Nutrition Program Adapted to the Practices of a Country. J Pain Symptom Manage 54:387-393.e3 . doi: 10.1016/j.jpainsymman.2017.01.010

24. Senesse P, Vasson M-P (2012) Nutrition chez le patient adulte atteint de cancer : quand et comment évaluer l'état nutritionnel d'un malade atteint de cancer ? Comment faire le diagnostic de dénutrition et le diagnostic de dénutrition sévère chez un malade atteint de cancer? Quelles sont les situations les plus à risque de dénutrition? Nutr Clin Métabolisme 26:165-188 . doi: 10.1016/j.nupar.2012.10.004 
25. Pressoir M, Desné S, Berchery D, et al (2010) Prevalence, risk factors and clinical implications of malnutrition in French Comprehensive Cancer Centres. Br J Cancer 102:966-971 . doi: 10.1038/sj.bjc.6605578

26. Senesse P, Hébuterne X (2012) Nutrition chez le patient adulte atteint de cancer : besoins nutritionnels, énergétiques et protéiques, au cours de la prise en charge du cancer chez l'adulte. Nutr Clin Métabolisme 26:189-196 . doi: 10.1016/j.nupar.2012.10.005 27. Ovesen L, Allingstrup L, Hannibal J, et al (1993) Effect of dietary counseling on food intake, body weight, response rate, survival, and quality of life in cancer patients undergoing chemotherapy: a prospective, randomized study. J Clin Oncol 11:2043-2049 28. Hutton JL, Martin L, Field CJ, et al (2006) Dietary patterns in patients with advanced cancer: implications for anorexia-cachexia therapy. Am J Clin Nutr 84:1163-1170 29. Hanley JA, McNeil BJ (1982) The meaning and use of the area under a receiver operating characteristic (ROC) curve. Radiology 143:29-36 . doi:

10.1148/radiology.143.1.7063747

30. Blundell J, de Graaf C, Hulshof T, et al (2010) Appetite control: methodological aspects of the evaluation of foods. Obes Rev 11:251-270 . doi: 10.1111/j.1467789X.2010.00714.X

31. Blauwhoff-Buskermolen S, Ruijgrok C, Ostelo RW, et al (2016) The assessment of anorexia in patients with cancer: cut-off values for the FAACT-A/CS and the VAS for appetite. Support Care Cancer 24:661-666 . doi: 10.1007/s00520-015-2826-2

32. Sunde B, Ericson J, Kumagai K, et al (2015) Relief of dysphagia during neoadjuvant treatment for cancer of the esophagus or gastroesophageal junction. Dis Esophagus. doi: $10.1111 /$ dote. 12352

33. Rahemtulla Z, Baldwin C, Spiro A, et al (2005) The palatability of milk-based and non-milk-based nutritional supplements in gastrointestinal cancer and the effect of 
chemotherapy. Clin Nutr 24:1029-1037 . doi: 10.1016/j.clnu.2005.08.003

34. Wilkie D, Lovejoy N, Dodd M, Tesler M (1990) Cancer pain intensity measurement: concurrent validity of three tools--finger dynamometer, pain intensity number scale, visual analogue scale. Hosp J 6:1-13

35. Hemati K, Zaman B, Hassani V, et al (2015) Efficacy of fentanyl transdermal patch in the treatment of chronic soft tissue cancer pain. Anesthesiol Pain Med 5:e22900 . doi: 10.5812/aapm. 22900

36. Eguchi K, Honda M, Kataoka T, et al (2014) Efficacy of corticosteroids for cancerrelated fatigue: A pilot randomized placebo-controlled trial of advanced cancer patients. Palliat Support Care 1-8 . doi: 10.1017/S1478951514001254

37. Bruera E, Kuehn N, Miller MJ, et al (1991) The Edmonton Symptom Assessment System (ESAS): a simple method for the assessment of palliative care patients. J Palliat Care 7:6-9

38. Aitken RC (1969) Measurement of feelings using visual analogue scales. Proc R Soc Med 62:989-993

39. Chaytor N, Schmitter-Edgecombe M (2003) The ecological validity of neuropsychological tests: a review of the literature on everyday cognitive skills. Neuropsychol Rev 13:181-197

40. Ginty AT (2013) Psychometric Properties. In: Gellman MD, Turner JR (eds) Encyclopedia of Behavioral Medicine. Springer New York, pp 1563-1564

41. Chambrier C, Sztark F, Société Francophone de nutrition clinique et métabolisme (SFNEP), Société française d'anesthésie et réanimation (SFAR) (2012) French clinical guidelines on perioperative nutrition. Update of the 1994 consensus conference on perioperative artificial nutrition for elective surgery in adults. J Visc Surg 149:e325-336 . doi: 10.1016/j.jviscsurg.2012.06.006 
42. Burke BS (1947) The dietary history as a tool in research. J Am Diet Assoc 10411046

43. Bingham SA, Gill C, Welch A, et al (1994) Comparison of dietary assessment methods in nutritional epidemiology: weighed records v. $24 \mathrm{~h}$ recalls, food-frequency questionnaires and estimated-diet records. Br J Nutr 72:619 . doi: 10.1079/BJN19940064 44. Haverkort EB, de Haan RJ, Binnekade JM, van Bokhorst-de van der Schueren MAE (2012) Self-reporting of height and weight: valid and reliable identification of malnutrition in preoperative patients. Am J Surg 203:700-707 . doi: 10.1016/j.amjsurg.2011.06.053 